\section{Commentary: Picking up the slack-The case for conservative management of postrepair systolic anterior motion}

\author{
Ehud Raanani, MD, and \\ Ehud Schwammenthal, MD, PhD
}

Primary abnormalities of the mitral valve apparatus constitute the root cause of systolic anterior motion (SAM) of the mitral valve, resulting in outflow tract obstruction and mitral regurgitation. ${ }^{1-3}$ In hypertrophic obstructive cardiomyopathy, the straightforward connection between altered geometry of the mitral valve and its dysfunction was long obscured by an overwhelming focus on asymmetric hypertrophy, particularly because septal myectomy abolishes SAM so efficiently. However, already early on, it was recognized that the surgical procedure corrects, to no small extent, the abnormal anterior displacement of the mitral valve within the ventricular cavity by relative posterior realignment with respect to the streamlines of flow. ${ }^{4}$ The subsequent observation of SAM after mitral valve repair in the absence of any left ventricular hypertrophy was a turning point in our mechanistic understanding of SAM. ${ }^{5,6}$ Once its root cause was recognized, surgical strategies could be developed to prevent this complication. ${ }^{7}$

In a large, contemporary cohort of patients, Ashikhmina and colleagues ${ }^{8}$ identified 3 geometric predictors favoring postrepair SAM: excessive posterior leaflet height (shifting the coaptation point anteriorly), small left ventricular systolic volume, and bileaflet prolapse. The first predictor is well recognized ${ }^{9}$ and has been addressed by resective measures; others favor neochordal restraint. ${ }^{10-13}$ The second most probably acts by moving the papillary muscles closer together and closer to the outflow tract,

From the Leviev Cardiothoracic and Vascular Center, Sheba Medical Center, Tel Hashomer, and Tel Aviv University, Ramat Aviv, Israel.

Disclosures: Authors have nothing to disclose with regard to commercial support.

Received for publication Feb 19, 2020; revisions received Feb 19, 2020; accepted for publication Feb 19, 2020; available ahead of print March 4, 2020.

Address for reprints: Ehud Raanani, MD, Cardiothoracic Surgery, Sheba Medical Center, Israel, Israel Society for Cardiothoracic Surgery, Tel-Aviv University,

Tel-Aviv, Israel (E-mail: ehud.raanani@sheba.health.gov.il).

J Thorac Cardiovasc Surg 2021;162:580-1

$0022-5223 / \$ 36.00$

Copyright (c) 2020 by The American Association for Thoracic Surgery

https://doi.org/10.1016/j.jtcvs.2020.02.082

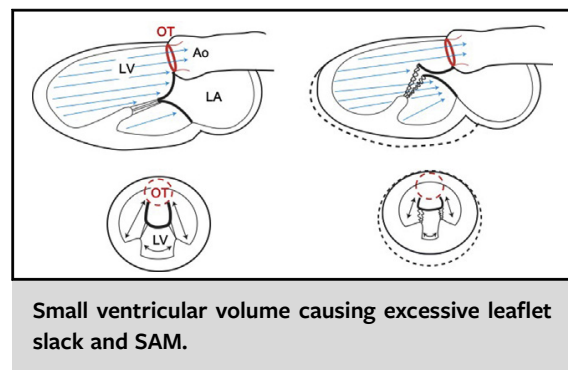

CENTRAL MESSAGE

SAM postrepair results from an anterior shift of leaflet coaptation. Surgical intervention is warranted in $\leq 1 \%$ of the total population, and outcome with conservative management is favorable.

producing excessive leaflet slack, while exposing the insufficiently tethered leaflets to the outflow stream (Figure 1). The third predictor may be related to the first: an unbalanced bileaflet prolapse with posterior dominance may cause an anterior shift of the valve. Not surprisingly, therefore, the surgical remedy in all cases included posterior leaflet intervention. In our series, with a more liberal use of artificial chordae $(60 \%)$, bileaflet prolapse was not a predictor of SAM. ${ }^{14}$ In fact, use of artificial chordae appeared to have a protective effect, indicating it may facilitate leaflet balance more predictably than by relying exclusively on resective techniques. ${ }^{14}$ Of note, the authors did not find an association between basal septum thickness and SAM. Concentric left ventricular hypertrophy may act only indirectly, by reducing systolic cavity size. Inappropriate small cavity size may be treated effectively by volume loading, beta-blockers, and/or vasoconstrictors. ${ }^{8,14}$

The initially observed SAM incidence of $13 \%$, about $60 \%$ greater than previously reported, ${ }^{14,15}$ included chordal, nonobstructive (and nonregurgitant) SAM, which, unlike true leaflet SAM, does not represent a clinical problem.

As in our series, the vast majority of patients were managed conservatively with favorable outcomes. Only about $3.6 \%$ of the total study population showed persistent SAM at discharge, and only $1 \%$ was discharged with SAM and moderate mitral regurgitation (using stress echocardiography, we could even demonstrate lack of a provokable 

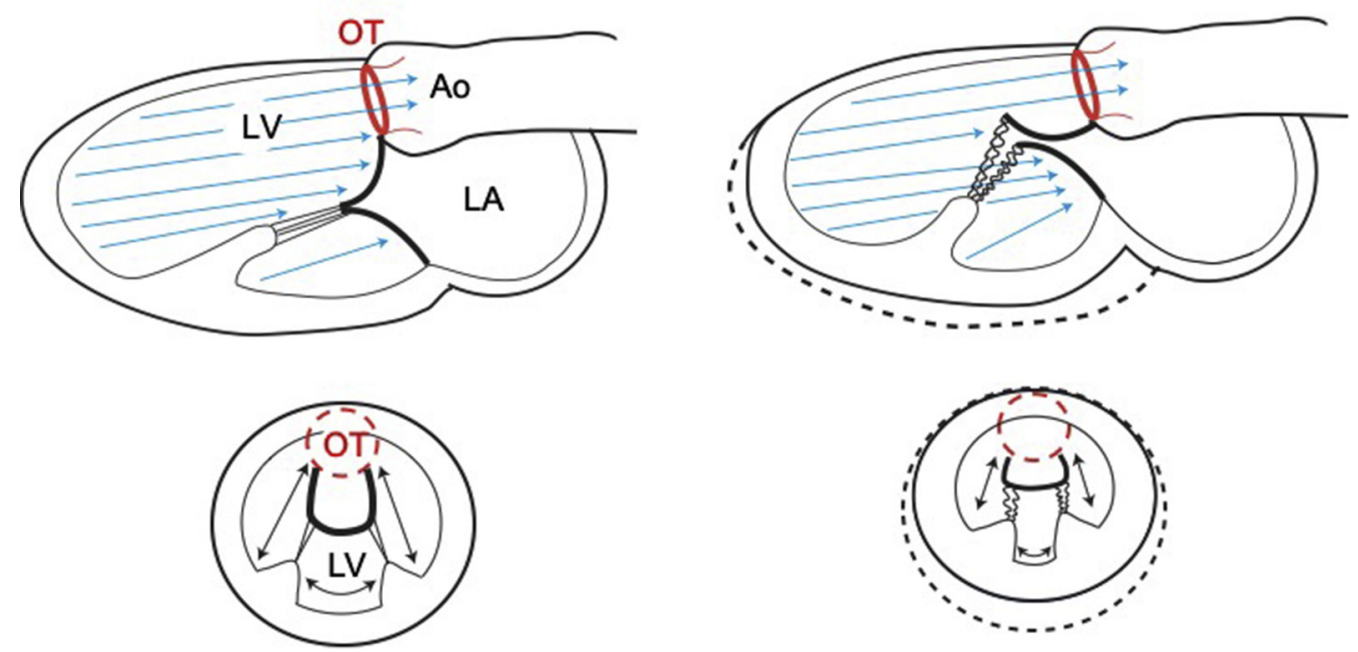

FIGURE 1. Mitral tethering in a normal (left) and small left ventricular cavity (right). Top: long-axis view; bottom: short-axis view. Left, with normal mitral tethering the streamlines of flow keep the valve in a posterior position. Right, a decrease in ventricular volume moves the papillary muscles closer together and closer to the outflow tract $(O T)$ (double arrows), producing excessive leaflet slack while exposing the insufficiently tethered leaflets to the outflow stream. The valve is pushed toward the septum. $L V$, Left ventricle; $A o$, aorta; $L A$, left atrium.

outflow tract obstruction at follow-up in patients with an initial tendency to $\mathrm{SAM}^{14}$ ).

We suspect these favorable numbers do not imply that there is rarely an a priori potential but rather that awareness of the problem by experienced surgical teams has led to its effective prevention. If, nonetheless, SAM occurs, it is in many cases a functional rather than structural problem, with volume loading and beta-blockers capable of picking up the slack.

\section{References}

1. Jiang L, Levine RA, King ME, Weyman AE. An integrated mechanism for systolic anterior motion of the mitral valve in hypertrophic cardiomyopathy based on echocardiographic findings. Am Heart J. 1987;113:633-44.

2. Levine RA, Vlahakes GJ, Lefebvre X, Guerrero JL, Cape EG, Yoganathan AP, et al. Papillary muscle displacement causes systolic anterior motion of the mitral valve. Experimental validation and insights into the mechanism of subaortic obstruction. Circulation. 1995;91:1189-95.

3. He S, Hopmeyer J, Lefebvre XP, Schwammenthal E, Yoganathan AP, Levine RA. Importance of leaflet elongation in causing systolic anterior motion of the mitral valve. J Heart Valve Dis. 1997;6:149-59.

4. Reis RL, Bolton MB, King JF, Pugh DM, Dunn MI, Mason DT. Anterior-superior displacement of papillary muscles producing obstruction and mitral regurgitation in idiopathic hypertrophic subaortic stenosis: operative relief by posteriorsuperior realignment of papillary muscles following ventricular septal myectomy. Circulation. 1973;50(suppl):I1181-8.
5. Termini BA, Jackson PA, Williams CD. Systolic anterior motion of the mitral valve following annuloplasty. Vasc Surg. 1977;11:55-60.

6. Bulkley BH, Fortuin NJ. Systolic anterior motion of the mitral valve without asymmetric septal hypertrophy. Chest. 1976;69:694-6.

7. Jebara VA, Mihaileanu S, Acar C, Brizard C, Grare P, Latremouille C, et al. Left ventricular outflow tract obstruction after mitral valve repair. Results of the sliding leaflet technique. Circulation. 1993;88(5 Pt 2):II30-I34.

8. Ashikhmina E, Schaff HV, Daly RC, Stulak JM, Greason KL, Michelena HI, et al. Risk factors and progression of systolic anterior motion after mitral valve repair J Thorac Cardiovasc Surg. 2021;162:567-77.

9. Maslow AD, Regan MM, Haering JM, Johnson RG, Levine RA. Echocardiographic predictors of left ventricular outflow tract obstruction and systolic anterior motion of the mitral valve after mitral valve reconstruction for myxomatous valve disease. J Am Coll Cardiol. 1999;34:2096-104.

10. Frater RW. 10th GoreTex chorda anniversary. J Heart Valve Dis. 1996;5: 348-51.

11. David TE. Replacement of chordae tendineae with expanded polytetrafluoroethylene sutures. J Card Surg. 1989:4:286-9.

12. von Oppell UO, Mohr FW. Chordal replacement for both minimally invasive and conventional mitral valve surgery using premeasured Gore-Tex loops. Ann Thorac Surg. 2000;70:2166-8.

13. Holubec T, Sündermann SH, Jacobs S, Falk V. Chordae replacement versus leaflet resection in minimally invasive mitral valve repair. Ann Cardiothorac Surg. 2013;2:809-13.

14. Kuperstein R, Spiegelstein D, Rotem G, Stein M, Kogan A, Sternik L, et al. Late clinical outcome of transient intraoperative systolic anterior motion post mitral valve repair. J Thorac Cardiovasc Surg. 2015;149:471-6.

15. Brown ML, Abel MD, Click RL, Morford RG, Dearani JA, Sundt TM, et al. Systolic anterior motion after mitral valve repair: is surgical intervention necessary? J Thorac Cardiovasc Surg. 2007;133:136-43. 